\title{
Effects of Exercise and Mindfulness-Based Yoga Programs on Promotion of Resilience and Mental Health of Older Adults in Japan: A Randomized Controlled Trial
}

\author{
Hiroko Kukihara ${ }^{*}$, Niwako Yamawaki' ${ }^{2}$ Michiyo Ando ${ }^{3}$, Midori Nishio", Kayoko Koga1, \\ Hiromi Kimura1, Takuro Matsuda ${ }^{5}$
}

\author{
${ }^{1}$ School of Nursing, Faculty of Medicine, Fukuoka University, Fukuoka, Japan \\ ${ }^{2}$ Department of Psychology, Brigham Young University, Provo, USA. \\ ${ }^{3}$ School of Nursing, St. Mary's College, Fukuoka, Japan \\ ${ }^{4}$ Japanese Red Cross Kyushu International College of Nursing, Fukuoka, Japan \\ ${ }^{5}$ Faculty of Spots and Health Science, Fukuoka University, Fukuoka, Japan \\ Email: ^hkukihara@adm.fukuoka-u.ac.jp
}

How to cite this paper: Kukihara, H., Yamawaki, N., Ando, M., Nishio, M., Koga, K., Kimura, H., \& Matsuda, T. (2020). Effects of Exercise and Mindfulness-Based Yoga Programs on Promotion of Resilience and Mental Health of Older Adults in Japan: A Randomized Controlled Trial. Psychology, 11, 285-298.

https://doi.org/10.4236/psych.2020.112018

Received: January 10, 2020

Accepted: February 8, 2020

Published: February 11, 2020

Copyright $\odot 2020$ by author(s) and Scientific Research Publishing Inc. This work is licensed under the Creative Commons Attribution International License (CC BY 4.0).

http://creativecommons.org/licenses/by/4.0/ (c) (i) Open Access

\begin{abstract}
The purpose of the present study was to investigate the mediating roles of resilience on the relationship between groups (exercise/mindfulness/control) and minor psychiatric disorders measured. Then, the effects of exercise and mindfulness-based yoga programs on resilience were examined using randomized control design. The data were collected from three community centers in Fukuoka, Japan, and a total of 55 participants, who were over 65 years of age and met inclusion criteria, were randomly assigned to one of the three groups. Then, the participants were asked to complete the demographic survey as well as the GHQ-12. The results of the path mediation analyses showed that resilience fully mediated the relationship between group and minor psychiatric disorders. Furthermore, there was a significant difference in resilience and psychiatric disorders between exercise/mindfulness groups and the control group, while there were no differences between the exercise and mindfulness-based yoga groups. Potential intervention programs are discussed.
\end{abstract}

\section{Keywords}

Resilience Promotion, Physical Exercise, Mindfulness-Based Yoga, Older Adults, Randomized Control Design 


\section{Introduction}

The world's population is continuously aging, and the pace of the aging population is unprecedently faster now than in the past. According to $\mathrm{He}$, Goodkind, and Kowal (2016), 8.5\% of people worldwide are aged 65 and over today, and this percentage is expected to increase to nearly $17 \%$ of the world's population by 2050 . Among all the countries in the world, Japan is known as the "super-aging society" (Muramatsu \& Akiyama, 2011), with 26\% of its population over the age of 65 in 2016, the highest share of senior citizens, and its over-65 population is expected to expand to more than 30\% in 2025 (Miranda, 2018). People are living much longer; however, this does not mean they are healthier. Healthy life expectancy, which is the number of healthy years spent without illness, is increasing at a far slower pace than aging itself (Murray et al., 2015). This means that people are living longer, but they are spending more of that time with physical and mental illnesses, and elderly individuals are at risk of chronic illness and poor well-being. Accordingly, researchers call for effective strategies to reduce these risks.

The process of aging can be very difficult, and researchers have tried to define what successful aging means. According to Bowling and Dieppe (2005), some use biomedical theories to define successful aging by optimizing life expectancy while minimizing physical and mental deterioration and disability. Therefore, their focuses are the absence of chronic disease, good health, autonomous physical functioning, performance, mobility, and cognitive functioning. As such, they recommend maximizing the duration of successful healthy life expectancy, which typically means free from chronic disease and disability, as well as high physical and mental functioning (MacLeod, Musich, Hawkins, Alsgaard, \& Wicker, 2016). Bowling and Dieppe (2005), however, pointed out the limitation of the biomedical model: that a disease-free older age is unrealistic for most people. Furthermore, 50\% of elderly people view themselves as having aged successfully, yet less than $20 \%$ can also be categorized with this traditional medical model.

Bowling and Dieppe (2005) then introduced another model: the psychosocial model of successful aging. The key components to successful aging for the biomedical model are the absence of disease and the maintenance of physical and mental functioning, while the psychosocial model emphasizes life satisfaction, social participation and functioning, and psychological resources. For the purpose of this study, we utilize this model for a few reasons. First, previous researchers have focused on subjective perceptions of successful aging and found that at least some older adults perceived they were aging successfully even though they were experiencing physical challenges (Bartley et al., 2019; Pruchno, Wilson-Genderson, \& Cartwright, 2010). Second, psychosocial factors, such as social isolation (Cornwell \& Waite, 2009) and positive self-perceptions (Levy, Slade, Kunkel, \& Kasl, 2002; Sargent-Cox, Anstey, \& Luszcz, 2012), have been recognized as having an independent influence on physical health outcomes. Fi- 
nally, the mechanisms of this approach are useful and amenable for intervention and are consequently helpful in reducing poor physical functioning outcomes. Growing research today focuses on one of the psychological resources of successful aging, resilience, since resilience has shown to be associated with good psychological and physiological well-being for older adults (Bartholomaeus et al., 2019; Johnston-Brooks, Lewis, \& Garg, 2002; Kukihara et al., 2018; Sousa, Zauszniewski, Musil, Price Lea, \& Davis, 2005).

Resilience is defined as a "fluid personality characteristic that enhances individual adaptation and positively influences the process of successful aging" (Wagnild, 2003: p. 43). Since resilience is an effective buffer on psychological and physical well-being despite adversity, researchers have called for strategies to promote resilience among older adults. Studies have revealed some predictive factors of resilience among older adults. For instance, Kukihara et al. (2018) indicated that physical activities and social support were both significant predictors for greater resilience. Others found that health promoting behavior, financial resources (Clark, Burbank, Greene, Owens, \& Riebe, 2011), optimism (Depp \& Jeste, 2006; Non et al., 2020), and mindfulness (Geschwind, Peeters, Drukker, van Os, \& Wichers, 2011) are all predictors of resilience. However, these studies are all correlational studies, and to our knowledge, there is currently a dearth of studies utilizing randomized control design to investigate the promotion of resilience among older adults in the literature. Therefore, the purpose of the present study was to investigate the mediating roles of resilience on the relationship between groups (exercise/mindfulness/control) and minor psychiatric disorders measured. Then, the effects of exercise and mindfulness-based yoga programs on resilience were examined using randomized control design.

\subsection{Resilience and Physical Activities}

Since resilience is a "fluid personality characteristic" rather than a trait, it is plausible that resilience can be promoted by physical activity. For instance, resilience was positively associated with physical activity among individuals who went through the catastrophic earthquake and tsunami in Japan in 2011 (Kukihara, Yamawaki, Uchiyama, Arai, \& Horikawa, 2014). Others also found that resilience can enhance older adults' adaptation and positively influence the process of better physical and mental health and positive views of aging (Hardy \& Gill, 2004). Indeed, researchers found a mediating effect of resilience between physical activity and depression severity (Yoshikawa, Nishi, \& Matsuoka, 2015). Therefore, it was hypothesized that individuals who were randomly assigned to an exercise group would show greater resilience in comparison to the control group.

\subsection{Resilience and Mindfulness}

Mindfulness-based programs have been used to treat psychiatric illnesses, such as anxiety and depression, and have shown that they indeed effectively reduce 
the severity of the symptoms (Hofmann, Sawyer, Witt, \& Oh, 2010; Johnson, Emmons, Rivard, Griffin, \& Dusek, 2015). Mindfulness is defined as the awareness of both mind and body through paying attention on purpose, focusing on moment-to-moment experiences without judgment, and being present in a given moment (Kabat-Zinn, 2013). Therefore, mindfulness interventions are frequently intended to support cultivation of awareness and focus on the present moment with acceptance and acknowledgment and without interpretation or emotional reaction (Johnson et al., 2015). Although there are many forms of mindfulness practices, the most common and popular methods are static meditation and mindful movement, such as yoga, since the purpose of both methods are aligned with the definition of mindfulness. There are promising effects of yoga-based mindful intervention on improvement of anxiety symptoms and memory among older adults (Lenze et al., 2014).

Since mindfulness-based yoga programs have shown encouraging results in improving older adults' psychological well-being, some researchers have investigated the link between mindfulness-based yoga programs and resilience. For instance, Brown and Ryan (2003) found that mindfulness practices, such as yoga and meditation, have beneficial effects on psychological resilience. Although Hartfiel, Havenhand, Khalsa, Clarke, and Krayer (2011) did not directly measure resilience, they showed that yoga was effective for enhancing emotional well-being and resilience regarding stress in the workplace. Furthermore, Kemper, Mo, and Khayat (2015) also revealed a significant positive relationship between mindfulness and resilience. Therefore, we hypothesized that individuals who were randomly assigned to a mindfulness-based yoga group would show superior resilience in comparison to the control group.

\section{Method}

\subsection{Participants/Procedure}

After receiving approval from the director of The Council of Social Welfare for Kashii District in Fukuoka Prefecture, Japan, recruitment flyers were posted at three community centers in the district. In the flyer, the purpose of this study, which was to evaluate one's physical and psychological well-being, and inclusion and exclusion criteria for participation were addressed. Participants in the present study were adults who were 65 years of age or older, could come to their community center, were able to complete the survey, and were not already exercising or practicing yoga more than once a week. Individuals who had severe dementia, who had been diagnosed with or were getting treatment for cardiovascular/respiratory diseases, and who had musculoskeletal problems, such as problems with muscles, bones, tendons, ligaments, joints, etc. in which the symptoms could be exacerbated by exercising were excluded. Further, individuals who were advised not to exercise by their doctors, who were undergoing dialysis, and who were evaluated as being unfit by the researchers were also excluded. Before being enrolled in the present study, potential participants were 
interviewed by the researchers, who were all nurses, to ensure that they met the inclusion/exclusion criteria. In addition, they were also told again the study purpose and asked their willingness to be randomly assigned to one of the three groups (control-50 minutes TV watching; mindfulness-50 minutes participation in mindfulness yoga program; and exercise -50 minutes cardiovascular exercise). They were also requested to come to the community centers once a week for 12 weeks to participate in one of the three group activities. After they completed their assigned program, they were asked to respond to the questionnaires. The demographic information of the participants is summarized in Table 1.

1) Exercise group. A total of 23 elderly individuals were assigned to the exercise group. This group was led by a health fitness programmer who had a doctoral degree in health fitness programing and was licensed to create and assist safe and effective exercise programs for elderly individuals. This instructor came to the community center once a week to assist participants with cardiovascular exercises using bicycles, treadmills, and warm-up/cool-down stretching. Each exercise session took place for about 50 minutes, and the instructor checked the participants' blood pressure before and after the exercises. Two individuals declined to participate in this group, so a total of 22 individuals completed the 12-week exercise program without any physical problems. All participants were instructed not to participate in any yoga programs.

Table 1. Demographic summary.

\begin{tabular}{|c|c|c|c|}
\hline & \multicolumn{3}{|c|}{$\mathrm{n}(\%)$, mean $\pm \mathrm{SD}$ [range] } \\
\hline & Control $\mathrm{n}=18$ & Exercise $\mathrm{n}=22$ & Yoga $n=15$ \\
\hline Age & $69.91 \pm 3.11[64-96]$ & $69.91 \pm 3.11[64-96]$ & $69.91 \pm 3.11[64-96]$ \\
\hline \multicolumn{4}{|l|}{ Gender } \\
\hline Male & $6(33)$ & $8(36)$ & $5(34)$ \\
\hline Female & $12(67)$ & $14(64)$ & $10(66)$ \\
\hline \multicolumn{4}{|l|}{ Marital status } \\
\hline Married/with partner & $13(72)$ & $17(77)$ & $11(73)$ \\
\hline No partner/divorced & $5(28)$ & $5(23)$ & $4(27)$ \\
\hline \multicolumn{4}{|l|}{ Living arrangement } \\
\hline Living alone & $7(38)$ & $3(14)$ & $4(27)$ \\
\hline Living with someone & $11(62)$ & $19(86)$ & $11(72)$ \\
\hline \multicolumn{4}{|l|}{ Education } \\
\hline Primary school & $7(39)$ & $9(41)$ & $5(34)$ \\
\hline$>$ High school & $11(61)$ & $13(59)$ & $10(66)$ \\
\hline \multicolumn{4}{|l|}{ Income, $¥$} \\
\hline$<2$ million & $9(50)$ & $12(56)$ & $8(53)$ \\
\hline$>2$ million & $9(50)$ & $10(44)$ & $7(47)$ \\
\hline
\end{tabular}


2) Mindfulness group. A total of 20 elderly participants were randomly assigned to the mindfulness group. For the present study, yoga was used to facilitate mindfulness practice since it has been linked to attention-focusing mindfulness (van der Kolk, 2006) and has represented living "in the present," which is the basic premise underlying mindfulness practices (Salmon, Lush, Jablonski, \& Sephton, 2009). A certified yoga therapist from the Japan Yoga Therapy Association instructed at a community center for a 50-minute session every week for 12 weeks. The yoga therapist followed the mindfulness yoga program that has been developed and used only for elderly individuals in a past study in Japan, and it included a combination of mindfulness and yoga slow movements such as breathing, light movements, and meditation (Ando, Kukihara, \& Tanaka, 2018). This program was deemed appropriate to differentiate the mindfulness group from the exercise group since movement sequences have been formulated to encourage mindful awareness, and they are done slowly and gently and are not overly physically taxing. Four participants dropped out from this program for various reasons, thus, a total of 15 participants completed the full program. In addition, all participants were told not to exercise other than participating this yoga program.

3) Control group. A total of 18 elderly individuals were randomly assigned to the control group. The participants in this group were told not to exercise or attend any yoga programs. They were requested to come to the community centers once a week for 12 weeks anytime they wanted to watch TV programs.

\subsection{Measurements}

1) The General Health Questionnaire-12 (GHQ-12). The 12-item General Health Questionnaire has been extensively used in a variety of settings worldwide, and validity and reliability of GHQ- 12 has been found using Japanese adults (Doi \& Minowa, 2003). It is a self-administered screening questionnaire used to detect the incidence of minor psychiatric disorders among non-psychiatric individuals. In particular, it is intended to evaluate respondents' general mental health over the last 4 weeks, and the scale items ask about levels of happiness, depression, anxiety, and sleep disturbance. Each item was rated on a 4-point Likert scale from 0 (much less than usual) to 3 (better than usual) in response to whether the respondents have experienced each symptom over the past 4 weeks. In the present study, a dichotomous scoring method was used, coding the responses of 0 and 1 as 0 and those of 2 and 3 as 1 since dichotomous scoring was used in Doi and Minowa's (2003) study to prove the validity and reliability for the Japanese version of GHQ-12. Therefore, total scores on the GHQ-12 ranged from 0 to 12, and higher scores are indicative of high levels of psychological distress. The internal consistency for the current study was .78.

2) The resilience scale. The resilience scale (RS) was purported to assess an individual's qualities that enable him or her to thrive in the face of adversity (Wagnild \& Young, 1993). It consists of 25 items, all of which have a 7-point Likert scale response ranging from 0 (strongly disagree) to 4 (strongly agree). The 
scale is rated based on how the participant has felt over the past month. The total score ranges from 0 - 100, with higher scores reflecting greater resilience. The RS has been widely used cross-culturally and has been proven to be highly reliable in Japan (Kukihara et al., 2018). The Cronbach's alpha of this scale in the present study was .96 .

\subsection{Data Analyses}

To examine our hypothesis that resilience would mediate the relationship between the three groups and minor psychiatric disorders, path-analytic mediation analyses were conducted using the guidelines developed by Baron and Kenny (1986). All measurements were centered prior to all analyses conducted in this study using the recommendation by Jaccard, Wan, and Turrisi (1990). To achieve a mediating effect, three requirements must be met. First, the predictor variable (group) must show a significant relationship with both the mediator (resilience) and the criterion variable (minor psychiatric disorders). Second, the mediator must show a significant relationship with the criterion variable. Finally, when the relationship between the mediator and the criterion is held constant, the previously significant relationship between the predictor variable and the criterion variable should be significantly reduced. Cohen and Cohen (1983) attested that the final criterion would be demonstrated in a significant indirect effect, which was examined by employing Sobel's (1982) approximate-significance test for the indirect effect. In order to test the group differences on minor psychiatric disorders and resilience, a MANOVA was employed, with the group and participant's gender as independent variables and psychiatric disorders and resilience as dependent variables.

\section{Results}

\subsection{Mediating Effects of Resilience on the Relationship between Group and Minor Psychiatric Disorders}

To test the hypothesis that resilience would mediate the relationship between group and psychiatric disorders, path-analytic mediation analyses were performed. The results revealed that all four requirements guided by Baron and Kenny (1986) were significant. That is, paths a, b, and c were all significant, and the formerly significant zero-order correlations between group and minor psychiatric disorders became nonsignificant when the correlation between resilience and group was held constant. Then, Sobel's (1982) test for indirect effect was performed, and the results showed that it was significant using a one-tailed test. The results showed that resilience fully mediated the association between group and minor psychiatric disorders $(z=2.41, p=.008)$. The path analysis is summarized in Figure 1.

\subsection{Effects of Exercise/Mindfulness on Minor Psychiatric Disorders and Resilience}

A 3 (exercise, mindfulness, control) $\times 2$ (male and female) MANOVA was per- 
formed on minor psychiatric disorders and resilience. This analysis revealed the significant main effect of group $(F[4,94]=3.82, p=.006)$. A follow-up ANOVA showed that there were significant effects of group on both resilience and minor psychiatric disorders $(F[2,54]=5.03, p=.01 ; F[2,54]=6.11, p=.004$, respectively). Tukey's post hoc analysis was also performed. As for resilience, this analysis revealed that there was no significant difference between the exercise group $(M=64.42, S D=16.43)$ and the mindfulness group $(M=64.20, S D=$ 15.90). However, there were significant differences between the exercise group $(M=64.42, S D=16.43)$ and the control group $(M=48.77, S D=17.22 ; p=.03)$, indicating that participants in the exercise group were likely to be more resilient in comparison to the control group. There was also a significant difference between the mindfulness group $(M=64.20, S D=15.90)$ and the control group ( $M$ $=48.77, S D=17.22 ; p=.01$ ), denoting that participants in the mindfulness group tended to be more resilient in comparison to control group. No significant main effect of gender or interaction effects were found $[F(1,54)=.18, n . s, F(2$, $54)=.81, n . s]$ on resilience.

Another Tukey's post hoc analysis was performed on minor psychiatric disorders. This analysis revealed a similar pattern: there was no significant difference between the exercise group $(M=1.08, S D=1.24)$ and the mindfulness group $(M=1.00, S D=1.30)$ on minor psychiatric disorders. Conversely, there were significant differences between the exercise group $(M=1.08, S D=1.24)$ and the control group $(M=2.95, S D=2.59 ; p=.03)$, indicating that participants in the exercise group were likely to have less psychiatric disorders in comparison to the control group. There was also a significant difference between the mindfulness group $(M=1.00, S D=1.30)$ and the control group $(M=2.95, S D=2.59$; $p=.006$ ), denoting that participants in the mindfulness group tended to show lesser levels of psychiatric disorders in comparison to the control group. No significant main effect of gender or interaction effects were found $[F(1,54)=.08$, n.s, $F(2,54)=.71, n . s]$ on psychiatric disorders.

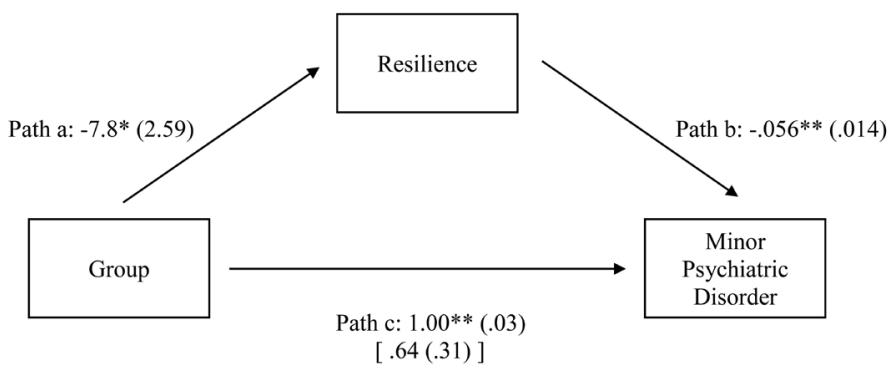

Figure 1. Summary of path analysis. Path model of the relationships among group (exercise/mindfulness/control), resilience, and minor psychiatric disorder. The numbers indicate the standard regression coefficient, and the numbers inside the parentheses represent standard errors. The numbers in the box brackets indicate the standard regression coefficient and standard error between group and minor psychiatric disorder after resilience was controlled for in the regression equation. Note. ${ }^{\star} p<.01 ;{ }^{\star *} p<.001$. 


\section{Discussion}

The World Health Organization (2019) attests that there is little evidence that elderly individuals are spending their later years in better health than their parents did, and that there is no significant change in the rate of disabilities. Therefore, concerned researchers call for effective strategies to maintain or improve successful aging. Since resilience can be one of the indispensable buffers for physical and mental health of elderly individuals and can be improved by physical exercise and/or mindfulness practices, the purpose of this study was to investigate the roles of exercise and mindfulness on resilience among elderly Japanese individuals. This study noteworthily utilized randomized control design while a majority of past studies used correlational research design to imply the roles of these practices.

As expected, the results from the preliminary analysis showed that resilience was a significant mediator for the relationships between both exercise and mindfulness-based yoga and minor psychiatric problems. Furthermore, when resilience was held constant, the relationship between exercise/mindfulness and minor psychiatric problem became nonsignificant. In other words, without having resilience through physical exercise and mindfulness, better mental well-being may not be achieved. This study showed that involvement in physical exercise and mindfulness increases one's resilience and such heightened resilience may lead to greater perceived mental health status.

Elavsky et al. (2005) asserted that physical exercise itself does not directly lead to one's perceived health status. Instead, underlying cognitive and emotional elements, such as resilience, may be a significantly influential factor when combined with exercise that leads to one's perceived mental well-being. This study affirmed their assertion, by using a randomized control method, that exercise and mindfulness lead to a significant improvement on resilience, which is a vital factor to improve one's mental health. The results of this study revealed that elderly participants, who were randomly assigned to either the exercise group or mindfulness-based yoga group, increased in resilience significantly more than the control group. The capacity to harness resilience-helping older adults to maintain in the face of challenges, to quickly recover from life difficulties related to aging, and to sustain quality of life in the face of declining physical and mental health in daily life-is one of the key factors for successful aging (Davis, 2009). To do so, even 50 minutes once a week of exercising and practicing mindfulness-based yoga for 12 weeks can improve older adults' mental well-being through improving resilience.

High resilience has been associated with successful aging, such as reduced depression and mortality risk (Martin, Distelberg, Palmer, \& Jeste, 2015) and better self-perceptions of aging successfully (Montross et al., 2006), as well as increased quality of life (Bowling \& Iliffe, 2011) and improved lifestyle behaviors (Smith \& Hollinger-Smith, 2015). Furthermore, resilience is significantly related to adaptive coping styles (Wu et al., 2013), optimism and hopefulness (Resnick \& In- 
guito, 2011), positive emotions (Martin et al., 2015; Tugade \& Fredrickson, 2004), social support, and community involvement (Gooding, Hurst, Johnson, \& Tarrier, 2012), as well as activities of daily living independence (Ahmed et al., 2018). Resilience is not only significantly associated with psychological well-being. It also impacts one's physical well-being, such as increased longevity (Shen \& Zeng, 2010) and faster recovery from cardiovascular diseases (Whitson et al., 2011). Since resilience is improved by exercising and mindfulness practices, we strongly recommend and encourage older adults to exercise or practice mindfulness to achieve successful aging to improve both physical and psychological well-being.

Another noteworthy study finding was that although participants in the exercise and mindfulness groups improved in resilience, which led to better mental well-being in comparison to the control group, there were no significant differences between these two groups on resilience and mental health. The average age of participants in this study was approximately 70, with an oldest of 76. In some studies, adults of age 85 and older seem to have the same or greater capacity for resilience as those who are younger (Hamarat et al., 2002), suggesting that resilience can be improved as long as older adults can exercise or practice mindfulness. When creating an intervention program to improve resilience for older adults, it is important to consider one's physical conditions regarding exercise and mindfulness. Since there was no difference between the exercise and mindfulness groups, one should evaluate the physical suitability of the participants.

There are some limitations in this study. Kukihara et al. (2018) revealed that better social support had significant impact on greater resilience. Our participants came to the community center nearest their residency and performed the task with other group members in both the exercise and mindfulness groups, while participants in the control group came to the center individually. During the twelve weeks of participation, participants in the exercise and mindfulness groups might have developed more social support in comparison to participants in the control group. Such group vs. individual tasks may influence the results of this study. Another limitation is that the participants of this study were healthy older adults who were not suffering from major diseases. It is recommended to create an intervention program to accommodate individuals with physical limitations since they are the one who need intervention the most. Finally, it would be better to replicate this study using a larger sample size.

\section{Conclusion}

This study was to investigate the mediating roles of resilience on the relationship between groups (exercise/mindfulness/control) and minor psychiatric disorders measured. Then, the effects of exercise and mindfulness-based yoga programs on resilience were further examined using randomized control design. The results indicated that even 50 minutes once a week of exercising and practicing mindfulness-based yoga for 12 weeks can improve older adults' mental well-being 
through improving resilience. Since resilience is improved by exercising and mindfulness practices, we strongly recommend and encourage older adults to exercise or practice mindfulness to achieve successful aging to improve both physical and psychological well-being.

\section{Conflicts of Interest}

The authors declare that they have no conflict of interest. The authors declare no support from any organization for the submitted work, no financial relationships with any organizations that might have an interest in the submitted work in the previous three years, and no other relationships or activities that could appear to have influenced the submitted work.

\section{References}

Ahmed, S. A., Shantharam, G., Eltorai, A. E., Hartnett, D. A., Goodman, A., \& Daniels, A. H. (2018). The Effect of Psychosocial Measures of Resilience and Self-Efficacy in Patients with Neck and Lower Back Pain. Spine Journal, 19, 232-237. https://doi.org/10.1016/j.spinee.2018.06.007

Ando, M., Kuhiharaa, H., \& Tanaka, C. (2018). Development of a Mindfulness Yoga Program and Effects on Cognitive Functions for the Community Dwelling Elderly. Annals of Nursing \& Practices, 5, 1100-1103.

Baron, R. M., \& Kenny, D. A. (1986). The Moderator-Mediator Variable Distinction in Social Psychological Research: Conceptual, Strategic, and Statistical Considerations. Journal of Personality and Social Psychology, 51, 1173-1182. https://doi.org/10.1037//0022-3514.51.6.1173

Bartholomaeus, J. D., Van Agteren, J. E. M., Iasiello, M. P., Jarden, A., \& Kelly, D. (2019). Positive Ageing: The Impact of a Community Well-Being and Resilience Program. Clinical Gerontologist, 42, 377-386. https://doi.org/10.1080/07317115.2018.1561582

Bartley, E. J., Palit, S., Fillingim, R. B., \& Robinson, M. E. (2019). Multisystem Resiliency as a Predictor of Physical and Psychological Functioning in Older Adults with Chronic Low Back Pain. Frontier Psychology, 10, 1932. https://doi.org/10.3389/fpsyg.2019.01932

Bowling, A., \& Dieppe, P. (2005). What Is Successful Ageing and Who Should Define It? British Medical Journal, 331, 1548-1551. https://doi.org/10.1136/bmj.331.7531.1548

Bowling, A., \& Iliffe, S. (2011). Psychological Approach to Successful Ageing Predicts Future Quality of Life in Older Adults. Health and Quality of Life Outcomes, 9, 13. https://doi.org/10.1186/1477-7525-9-13

Brown, K. W., \& Ryan, R. M. (2003). The Benefits of Being Present: Mindfulness and Its Role in Psychological Well-Being. Journal of Personality and Social Psychology, 84, 822-848. https://doi.org/10.1037/0022-3514.84.4.822

Clark, P. G., Burbank, P., Greene, G., Owens, N., \& Riebe, D. (2011). What Do We Know about Resilience in Older Adults? An Exploration of Some Facts, Factors, and Facets. In B. Resnick, K. Roberto, \& L. Gwyther (Eds.), Resilience in Aging: Concepts, Research, and Outcomes (pp. 51-66). New York: Springer.

https://doi.org/10.1007/978-1-4419-0232-0 4

Cohen, J., \& Cohen, P. (1983). Applied Multiple Regression/Correlation Analysis for the Behavioral Sciences (2nd ed.). Hillsdale, NJ: Lawrence Erlbaum.

Cornwell, E. Y., \& Waite, L. J. (2009). Measuring Social Isolation among Older Adults 
Using Multiple Indicators from the NSHAP Study. The Journals of Gerontology: Series B, 64, i38-i46. https://doi.org/10.1093/geronb/gbp037

Davis, M. C. (2009). Building Emotional Resilience to Promote Health. American Journal of Lifestyle Medicine, 3, 60S-63S. https://doi.org/10.1177/1559827609335152

Depp, C. A., \& Jeste, D. V. (2006). Definitions and Predictors of Successful Aging: A Comprehensive Review of Larger Quantitative Studies. The American Journal of Geriatric Psychiatry, 14, 6-20. https://doi.org/10.1097/01.JGP.0000192501.03069.bc

Doi, Y., \& Minowa, M. (2003). Factor Structure of the 12-Item General Health Questionnaire in the Japanese General Adult Population. Psychiatry and Clinical Neurosciences, 57, 379-383. https://doi.org/10.1046/j.1440-1819.2003.01135.x

Elavsky, S., McAuley, E., Motl, R. W., Konopack, J. F., Marquez, D. X., Hu, L., Diener, E. et al. (2005). Physical Activity Enhances Long-Term Quality of Life in Older Adults: Efficacy, Esteem, and Affective Influences. Annals of Behavioral Medicine, 30, 138-145. https://doi.org/10.1207/s15324796abm3002 6

Geschwind, N., Peeters, F., Drukker, M., van Os, J., \& Wichers, M. (2011). Mindfulness Training Increases Momentary Positive Emotions and Reward Experience in Adults Vulnerable to Depression: A Randomized Controlled Trial. Journal of Consulting and Clinical Psychology, 79, 618-628. https://doi.org/10.1037/a0024595

Gooding, P. A., Hurst, A., Johnson, J., \& Tarrier, N. (2012). Psychological Resilience in Young and Older Adults. International Journal of Geriatric Psychiatry, 27, 262-270. https://doi.org/10.1002/gps.2712

Hamarat, E., Thompson, D., Aysan, F., Steele, D., Matheny, K., \& Simons, C. (2002). Age Differences in Coping Resources and Satisfaction with Life among Middle-Aged, Young-Old, and Oldest-Old Adults. The Journal of Genetic Psychology, 163, 360-370. https://doi.org/10.1080/00221320209598689

Hardy, S. E., \& Gill, T. M. (2004). Recovery from Disability among Community-Dwelling Older Persons. Journal of the American Medical Association, 291, 1596-1602. https://doi.org/10.1001/jama.291.13.1596

Hartfiel, N., Havenhand, J., Khalsa, S. B., Clarke, G., \& Krayer, A. (2011). The Effectiveness of Yoga for the Improvement of Well-Being and Resilience to Stress in the Workplace. Scandinavian Journal of Work and Environmental Health, 37, 70-76. https://doi.org/10.5271/sjweh.2916

He, W., Goodkind, D., \& Kowal, P. (2016). An Aging World: 2015 (International Population Reports, P95/16-1). Washington DC: U.S. Census Bureau, U.S. Government Publishing Office.

Hofmann, S. G., Sawyer, A. T., Witt, A. A., \& Oh, D. (2010). The Effect of Mindfulness-Based Therapy on Anxiety and Depression: A Meta-Analytic Review. Journal of Consulting and Clinical Psychology, 78, 169-183. https://doi.org/10.1037/a0018555

Jaccard, J., Wan, C. K., \& Turrisi, R. (1990). The Detection and Interpretation of Interaction Effects between Continuous Variables in Multiple Regression. Multivariate Behavioral Research, 25, 467-478. https://doi.org/10.1207/s15327906mbr2504_4

Johnson, J. R., Emmons, H. C., Rivard, R. L., Griffin, K. H., \& Dusek, J. A. (2015). Resilience Training: A Pilot Study of a Mindfulness-Based Program with Depressed Healthcare Professionals. Explore: The Journal of Science \& Healing, 11, 433-444.

https://doi.org/10.1016/j.explore.2015.08.002

Johnston-Brooks, C. H., Lewis, M. A., \& Garg, S. (2002). Self-Efficacy Impacts Self-Care and HbA1c in Young Adults with Type I Diabetes. Psychosomatic Medicine, 64, 43-51. https://doi.org/10.1097/00006842-200201000-00007 
Kabat-Zinn, J. (2013). Full Catastrophe Living: Using the Wisdom of Your Body and Mind to Face Stress, Pain, and Illness (2nd ed.). New York: Random House.

Kemper, K. J., Mo, X., \& Khayat, R. (2015). Are Mindfulness and Self-Compassion Associated with Sleep and Resilience in Health Professionals? The Journal of Alternative and Complementary Medicine, 21, 496-503. https://doi.org/10.1089/acm.2014.0281

Kukihara, H., Yamawaki, N., Ando, M., Tamura, Y., Arita, K., \& Nakashima, E. (2018). The Mediating Effects of Resilience, Morale, and Sense of Coherence between Physical Activity and Perceived Physical/Mental Health among Japanese Community-Dwelling Older Adults: A Cross-Sectional Study. Journal of Aging and Physical Activity, 26, 544-552. https://doi.org/10.1123/japa.2017-0265

Kukihara, H., Yamawaki, N., Uchiyama, K., Arai, S., \& Horikawa, E. (2014). Trauma, Depression, and Resilience of Earthquake/Tsunami/Nuclear Disaster Survivors of Hirono, Fukushima, Japan. Psychiatry and Clinical Neurosciences, 68, 524-533.

https://doi.org/10.1111/pcn.12159

Lenze, E. J., Hickman, S., Hershey, T., Wendleton, L., Ly, K., Dixon, D., Dore, P., Wetherell, J. L. et al. (2014). Mindfulness-Based Stress Reduction for Older Adults with Worry Symptoms and Co-Occurring Cognitive Dysfunction. International Journal of Geriatric Psychiatry, 29, 991-1000. https://doi.org/10.1002/gps.4086

Levy, B. R., Slade, M. D., Kunkel, S. R., \& Kasl, S. V. (2002). Longevity Increased by Positive Self-Perceptions of Aging. Journal of Personality and Social Psychology, 83, 261-270. https://doi.org/10.1037//0022-3514.83.2.261

MacLeod, S., Musich, S., Hawkins, K., Alsgaard, K., \& Wicker, E. R. (2016). The Impact of Resilience among Older Adults. Geriatric Nursing, 37, 266-272.

https://doi.org/10.1016/j.gerinurse.2016.02.014

Martin, A. S., Distelberg, B., Palmer, B. W., \& Jeste, D. V. (2015). Development of a New Multidimensional Individual and Interpersonal Resilience Measure for Older Adults. Aging \& Mental Health, 19, 32-45. https://doi.org/10.1080/13607863.2014.909383

Miranda, A. E. R. (2018). Finding Opportunities in Japan's Aging Population. CIRSS Commentaries, 5, 1-3. http://hdl.handle.net/11540/8274

Montross, L. P., Depp, C., Daly, J. Reichstadt, J., Golshan, S., Moore, D., Jeste, D. V. et al. (2006). Correlates of Self-Rated Successful Aging among Community-Dwelling Older Adults. American Journal of Geriatric Psychiatry, 14, 43-51.

https://doi.org/10.1097/01.JGP.0000192489.43179.31

Muramatsu, N., \& Akiyama, H. (2011). Japan: Super-Aging Society Preparing for the Future. Gerontologist, 51, 425-432. https://doi.org/10.1093/geront/gnr067

Murray, C. J., Barber, R. M., Foreman, K. J., Ozgoren, A. A., Abd-Allah, F., Abera, S. F., Abu-Rmeileh, N. M. et al. (2015). Global, Regional, and National Disability-Adjusted Life Years (DALYs) for 306 Diseases and Injuries and Healthy Life Expectancy (HALE) for 188 Countries, 1990-2013: Quantifying the Epidemiological Transition. The Lancet, 386, 2145-2191. https://doi.org/10.1016/S0140-6736(15)61340-X

Non, A. L., Roman, J. C., Clausing, E. S., Gilman, S. E., Louks, E. B., Buka, S. L., \& Apple, A. A. (2020). Optimism and Social Support Predict Healthier Adult Behavior Despite Socially Disadvantaged Childhood. International Journal of Behavioral Medicine, 1-13. https://doi.org/10.1007/s12529-020-09849-w

Pruchno, R. A., Wilson-Genderson, M., \& Cartwright, F. (2010). A Two-Factor Model of Successful Aging. The Journals of Gerontology: Series B, 65, 671-679.

https://doi.org/10.1093/geronb/gbq051

Resnick, B. A., \& Inguito, P. L. (2011). The Resilience Scale: Psychometric Properties and Clinical Applicability in Order Adults. Archives of Psychiatric Nursing, 25, 11-20. 
https://doi.org/10.1016/j.apnu.2010.05.001

Salmon, P., Lush, E., Jablonski, M., \& Sephton, S. E. (2009). Yoga and Mindfulness: Clinical Aspects of an Ancient Mind/Body Practice. Cognitive and Behavioral Practice, 16, 59-72. https://doi.org/10.1016/j.cbpra.2008.07.002

Sargent-Cox, K. A., Anstey, K. J., \& Luszcz, M. A. (2012). The Relationship between Change in Self-Perceptions of Aging and Physical Functioning in Older Adults. Psychology and Aging, 27, 750-760. https://doi.org/10.1037/a0027578

Shen, K., \& Zeng, Y. (2010). The Association between Resilience and Survival among Chinese Elderly. Demographic Research, 23, 105-116.

https://doi.org/10.4054/DemRes.2010.23.5

Smith, J. L., \& Hollinger-Smith, L. (2015). Savoring, Resilience, and Psychological Well-Being in Older Adults. Aging and Mental Health, 19, 192-200. https://doi.org/10.1080/13607863.2014.986647

Sobel, M. E. (1982). Asymptotic Intervals for Indirect Effects in Structural Equations Models. In S. Leinhart (Ed.), Sociological Methodology (pp. 290-312). San Francisco, CA: Jossey-Bass. https://doi.org/10.2307/270723

Sousa, V. D., Zauszniewski, J. A., Musil, C. M., Price Lea, P. J., \& Davis, S. A. (2005). Relationships among Self-Care Agency, Self-Efficacy, Self-Care, and Glycemic Control. Research and Theory for Nursing Practice, 19, 217-230. https://doi.org/10.1891/rtnp.2005.19.3.217

Tugade, M. M., \& Fredrickson, B. L. (2004). Resilient Individuals Use Positive Emotions to Bounce Back from Negative Emotional Experiences. Journal of Personality and Social Psychology, 86, 320-333. https://doi.org/10.1037/0022-3514.86.2.320

van der Kolk, B. A. (2006). Clinical Implications of Neuroscience Research in PTSD. Annals of the New York Academy of Sciences, 1071, 277-293. https://doi.org/10.1196/annals.1364.022

Wagnild, G. (2003). Resilience and Successful Aging: Comparison among Low and High Income Older Adults. Journal of Gerontological Nursing, 29, 42-49. https://doi.org/10.3928/0098-9134-20031201-09

Wagnild, G., \& Young, H. M. (1993). Development and Psychometric Evaluation of the Resilience Scale. Journal of Nursing Measurement, 1, 165-178.

Whitson, H. E., Thielke, S., Diehr, P., O’Hare, A. M. Chaves, P. H. M., Zakai, N. A., Newman, A. B. et al. (2011). Patterns and Predictors of Recovery from Exhaustion in Older Adults: The Cardiovascular Health Study. Journal of the American Geriatrics Society, 59, 207-213. https://doi.org/10.1111/j.1532-5415.2010.03238.x

World Health Organization (2019). Summary: The World Report on Ageing and Health. Geneva: 6.

https://apps.who.int/iris/bitstream/handle/10665/186468/WHO FWC ALC 15.01 en g.pdf;jsessionid=DD4ECAA5D1E46BD850AFD21C88E88F6E? sequence $=1$

Wu, G., Feder, A., Cohen, H., Kim, J. J., Calderon, S., Charney, D. S., \& Mathé, A. A. (2013). Understanding Resilience. Frontiers in Behavioral Neuroscience, 7, 10. https://doi.org/10.3389/fnbeh.2013.00010

Yoshikawa, E., Nishi, D., \& Matsuoka, Y. (2015). Fish Consumption and Resilience to Depression in Japanese Company Workers: A Cross-Sectional Study. Lipids in Health and Disease, 14, 51-57. https://doi.org/10.1186/s12944-015-0048-8 